\title{
marges Marges
}

revue d'art contemporain Revue d'art contemporain

19 | 2014

Les temps de l'art

\section{«Peter Downsbrough»}

Sérignan, Musée Régional d'Art Contemporain du Languedoc-Roussillon, $1^{\mathrm{er}}$ mars - 11 juin 2014

\section{Émeline Jaret}

\section{(2) OpenEdition}

1 Journals

Édition électronique

URL : http://journals.openedition.org/marges/956

DOI : $10.4000 /$ marges.956

ISSN : 2416-8742

\section{Éditeur}

Presses universitaires de Vincennes

\section{Édition imprimée}

Date de publication : 1 octobre 2014

Pagination : 156-157

ISBN : 978-2-84292-415-7

ISSN : 1767-7114

\section{Référence électronique}

Émeline Jaret, « «Peter Downsbrough » », Marges [En ligne], 19 | 2014, mis en ligne le 01 octobre 2014, consulté le 24 septembre 2020. URL : http://journals.openedition.org/marges/956 ; DOI : https:// doi.org/10.4000/marges.956 


\section{«Peter Downsbrough »}

\section{Sérignan, Musée Régional d'Art Contemporain du Languedoc-Roussillon, $1^{\text {er }}$ mars - 11 juin 2014}

Architecte de formation, né en 1940, Peter Downsbrough débute sa carrière artistique à New York au début des années 1960, appartenant à la même génération que les pionniers de l'art conceptuel et exposant avec eux, tout en se tenant rapidement en marge du mouvement. S'il est américain de naissance, Peter Downsbrough vit depuis 1989 à Bruxelles et partage une longue histoire avec la scène artistique francophone. Il expose en France pour la première fois en 1973, puis régulièrement aux côtés d'artistes tels que Daniel Buren, François Morellet ou Claude Rutault, dont il partage les interrogations sur l'espace de présentation de l'œuvre d'art. Rien d'étonnant donc de le voir aussi présent en France en ce début d'année 2014, où prennent place trois expositions personnelles. Celles organisées par deux galeries parisiennes (la galerie Martine Aboucaya du 25 janvier au 22 février 2014, et la galerie des Multiples du 25 janvier au 25 mars 2014) fonctionnent comme des préambules de l'importante exposition monographique qui s'est tenue au Musée régional d'art contemporain du Languedoc-Roussillon (Sérignan) du $1^{\text {er }}$ mars au 11 juin 2014, l'une des plus complètes sur l'œuvre de Peter Downsbrough jamais organisée encore en France.

Construits autour d'une articulation entre des éléments langagiers et un vocabulaire géométrique, les dispositifs de Peter Downsbrough occupent tant l'espace externe du lieu d'exposition qu'ils ne recouvrent l'intégralité de ses surfaces internes et se développent sur des supports aussi variés que complémentaires. Ce travail tire son origine de l'apparition des Two Pipes en 1969-1970, sculpture constituée de deux tuyaux en métal de longueurs différentes, plantés dans le sol parallèlement l'un à l'autre. L'expérimentation des Two Pipes se poursuit jusqu'en 1978, inaugurant l'usage des deux lignes parallèles, forme emblématique de l'artiste qui recouvrent progressivement de multiples supports: on les retrouve dans des dessins sur papier, imprimées sur des cartes postales, elles se multiplient dans les livres qu'il 
réalise, etc. Elles signifient aussi l'intérêt de Peter Downsbrough pour la dualité, ainsi qu'il le déclare dans l'un de ses rares entretiens, donné en 1990 à la revue lilloise Sans Titre. Cet attrait pour la dualité est renforcé par l'association d'éléments linguistiques aux dispositifs sculpturaux, puisque le mot apparaît dans son œuvre en même temps que la série des Two Pipes, d'abord imprimé dans ses premiers livres (notamment Notes on Location, 1972), puis inscrit dans l'espace d'exposition à partir du milieu des années 1970. Cette association ne devient (quasi) systématique qu'à la fin des années 1970, quand les deux tuyaux métalliques des Two Pipes sont utilisés dans de nouvelles configurations, très vite rejoints par des dispositifs muraux réalisés avec des rubans adhésifs noirs qui s'étendent bientôt pour créer des Room pieces. Ces pièces, comme les précédentes, démontrent le processus de "défocalisation» comme le définit Michel Gauthier engagé par des artistes tels que Peter Downsbrough, pour qui l'œuvre ne constitue plus le point central de l'espace de sa présentation mais doit prendre en compte celui-ci ("l'espace laissé autour et entre les œuvres », comme l'écrit Daniel Buren dans Rebondissements en 1977). C'est pourquoi les dispositifs de Peter Downsbrough fonctionnent aussi bien dans l'espace urbain, dont la multiplication des éléments géométriques est également mise en valeur par les photographies qu'il prend à partir des années 1970, ainsi que dans ses vidéos.

C'est la continuité d'une telle réflexion, entreprise depuis la fin des années 1960, que l'exposition de Sérignan met en lumière. Les lignes et les mots de l'artiste se développent dans et au-delà de l'espace d'exposition: débutant sur le parvis à l'extérieur, ils montrent la voie au visiteur depuis l'accueil et la librairie vers les deux niveaux du musée où, investissant toutes les surfaces architecturales disponibles, ils recouvrent murs, sols et plafonds. Miroir d'une œuvre multifacette, l'exposition montre la variété des formes dont témoigne l'œuvre de Peter Downsbrough malgré un vocabulaire relativement réduit (tuyaux métalliques, rubans adhésifs noirs, photographies en noir et blanc, etc.). La première grande salle du musée présente un ensemble de Wall pieces qui, jouant avec les colonnes du musée, font face à d'importantes séries de photographies. À l'étage, la visite se poursuit par le cabinet d'arts graphiques qui rassemble de nombreux travaux sur papier ou carton, des cartes postales ainsi que des boîtes et jeux de dés. Deux salles de projection de vidéos encadrent celles où se développent plusieurs Room pieces, jouant de l'articulation de rubans adhésifs ou de tuyaux métalliques et de mots. Enfin, dans la dernière salle se trouve, outre des dessins sur papier, une série de maquettes sont placées à 1,50 $\mathrm{m}$ du sol. L'ensemble du dispositif expositionnel contribue à mettre en lumière la cohésion de cet œuvre qui, refusant le point de vue unique et se répétant sans cesse en faisant dialoguer les divers médias, interroge depuis près de 55 ans la spatialité du langage. Les nombreux échos formels et le choix des mots qui peuplent ces dispositifs tendent à renforcer l'image d'un travail qui s'emploie continuellement à faire se répondre les éléments entre eux et avec leur surface d'inscription, jouant avec les notions de renvoi, d'écart et d'espacement. Les deux pièces qui ouvrent et ferment l'exposition en témoignent: alors que sur le parvis du musée, la conjonction «ET » rassemble deux tuyaux métalliques dont le plus long est planté dans le sol, la dernière Room piece joue sur la double lecture du mot « TRACÉ/ÉCART».

\section{Emeline Jaret}

